\title{
Algunas claves de la reforma del Estatuto Jurídico Civil del animal en España
}

\author{
Benito Aláez Corral (LL.M. RUB)
}

Catedrático de Derecho Constitucional en la Universidad de Oviedo

Miembro de la Comisión de Derecho Animal del Colegio de Abogados de Oviedo

Cofundador del Observatorio Justicia y Defensa Animal

Asesor del Non Human Rights Project

Recepción: Mayo 2018

Aceptación: Junio 2018

\section{Resumen}

Este trabajo es una reelaboración de la parte introductoria al Informe sobre la reforma del Estatuto Jurídico Civil de los animales en España, que fue entregado en el Congreso de los Diputados durante la preparación de la Proposición de Ley de reforma del Código Civil sobre el régimen jurídico de los animales, actualmente en tramitación. En él se adelantan las razones legales que avalan el cambio del actual anticuado y atrasado estatuto jurídico civil de los animales como meras "cosas" y el contexto de derecho comparado en el que esto tiene lugar, así como las líneas maestras de los cambios en el Código Civil que pretende esta Proposición de Ley de reforma.

Palabras clave: código civil, estatuto jurídico de los animales, sintiencia, derecho animal, derecho comparado.

Abstract. Some Clues of the Ongoing Legal Change of Animal Civil Law Status in Spain.

This text is an elaborated version of the introductory part of the Report to the changing of the civil law status of animals in Spain, which was submitted to the Spanish Congress of Deputies during the drafting of the ongoing Bill to amend the Civil Code regarding the legal status of animals. It advances the legal reasons for changing the current outdated and oldfashioned civil law status of animals as mere "things" and the comparative law context in which this should take place, as well as the concrete Civil Code provisions this Bill aims to change..

Keywords: civil code, legal status of animals, sentience, animal law, comparative law. 


\title{
SUMARIO
}

\author{
1. Introducción \\ 2. Algunas consideraciones a propósito de la reforma del Estatuto Jurídico Civil del \\ animal \\ 3. Propuesta de reforma contenidas en la proposición de ley.
}

\section{INTRODUCIÓN}

Los estudios de opinión revelan una creciente preocupación de la sociedad europea por el bienestar de los animales, también de la española, que, sin embargo, confía más en las instituciones de la Unión Europea que en las nacionales para dicha tarea ${ }^{1}$. No solo, pero en buena medida también, ello se debe a que nuestro ordenamiento jurídico, como parte de la cultura social en transformación, no aparece como adecuadamente adaptado a esa función de proteger a los animales y a los intereses de estos, al menos ante los ojos de una sociedad española en la que conviven con los seres humanos millones de animales domésticos y de compañía.

Aunque se han tratado de ir paliando en los últimos tiempos con diversas reformas legislativas a nivel nacional y autonómico, las deficiencias normativas son muchas y abarcan diversos sectores del ordenamiento jurídico, desde el administrativo, con una patente falta de armonización de la legislación autonómica de protección animal mediante una ley de bases en esta materia, hasta el civil, en el que aún pervive un estatuto jurídico decimonónico que concibe a los animales como cosas.

Precisamente en este último ámbito es en el que la sociedad civil, mediante la exitosa campaña (\#AnimalesNOsonCosas), impulsada por el Observatorio Justicia y Defensa Animal $^{2}$ y la Fundación Affinity ${ }^{3}$ y con ya más de 300.000 apoyos, pero también las instituciones políticas mediante la aprobación unánime de una Enmienda Transaccional a una Proposición No de Ley de 14 de febrero de 2017, han decidido recientemente dar un paso al frente para tratar de adecuar el estatuto jurídico civil de los animales a la percepción social mayoritaria que los contempla como seres sintientes (sentient beings) y no como cosas.

En 2017 Observatorio Justicia y Defensa Animal \& Fundación Affinity promovieron la elaboración de un informe jurídico titulado: Informe sobre la reforma del Estatuto Jurídico Civil de los animales en España, que trataba de contribuir con un modesto análisis técnico a la labor gubernativa y parlamentaria de presentar y aprobar un proyecto de Ley de reforma

\footnotetext{
${ }^{1}$ Cfr. Eurobarómetro 2016 sobre la posición de los europeos hacia el bienestar animal http://ec.europa.eu/commfrontoffice/publicopinion/index.cfm/ResultDoc/download/DocumentKy/7134 8

${ }^{2}$ El Observatorio Justicia y Defensa Animal es una organización española, sin ánimo de lucro, de defensa legal de los animales que promueve el conocimiento del Derecho Animal, el impulso de reformas legales y la lucha contra el maltrato animal en España. El Observatorio inició esta campaña en 2015 en la plataforma Change.org para promover la modernización del estatuto jurídico civil de los animales en España. www.justiciaydefensaanimal.es

${ }^{3}$ La Fundación Affinity es una entidad privada sin ánimo de lucro creada en 1987. La Fundación tiene como misión investigar y divulgar los beneficios del vínculo entre personas y animales de compañía y llevar a cabo proyectos de acción social, especialmente en temas de abandono, adopción y terapias asistidas por animales de compañía. http://www.fundacion-affinity.org/
} 
del Código Civil que diese concreta respuesta jurídica a la unánime ${ }^{4}$ voluntad política expresada por el Congreso de los Diputados en la mencionada Proposición No de Ley. En este informe se analizan por expertos de los respectivos países cómo han sido las dos últimas reformas del estatuto jurídico civil de los animales llevadas a cabo en Francia y Portugal. La parte francesa ha sido elaborada por el abogado francés especializado en Derecho Animal, Loïs Lelanchon y la parte lusa, por la abogada portuguesa, también experta en Derecho Animal, Alexandra Reis Moreira; una segunda parte elaborada por la abogada experta en Derecho Animal, Nuria Menéndez de Llano, en la que aborda tanto el estatuto jurídico actual del animal en el Código Civil de 1889, como las concretas razones técnico jurídicas que avalan necesidad de actualizar también en nuestro país ese estatuto jurídico civil de los animales; el informe concluye con una parte elaborada conjuntamente por la abogada Menéndez de Llano y el que suscribe, en la que se sintetizan las conclusiones a las que se puede llegar y se formulan tentativamente unas concretas propuestas de reforma legal del Código Civil que, lógicamente, deberán ser valoradas y perfiladas por el Parlamento en la tramitación de la Proposición de Ley presentada.

Interesa destacar, en primer término, que los países cuyas reformas del Código Civil se han analizado en el informe -Francia y Portugal- se han seleccionado fundamentalmente por dos razones: de un lado porque son las dos reformas más recientes y por tanto las que pueden tener más y mejor en cuenta las expectativas de la sociedad en esta segunda década del siglo XXI. Piénsese que los otros países europeos que ya habían abordado la reforma del estatuto jurídico civil de los animales, Alemania, Austria y Suiza, lo habían hecho a principios de la década de 2000 y por tanto ya distan casi dos décadas desde que lo hicieran. Pero, de otro lado, además, se han escogido estos dos países porque los mismos pertenecen al modelo de Código Civil napoleónico al que también pertenece nuestro Código Civil, y no al modelo de Código Civil germánico de Alemania, Austria y Suiza. Ello hace que las soluciones y fórmulas escogidas por los ordenamientos francés y portugués puedan encajar mejor con la estructura y contenido del Código Civil español.

También se debe hacer mención a que en el caso de la modificación del Código Civil francés, la misma es muy parca y escueta porque la mayor parte de las modificaciones del estatuto jurídico civil de los animales en el ámbito agropecuario se habían hecho ya desde 1976 a través del Código Rural y de pesca marítima, que contiene disposiciones relativas al comercio y utilización de animales separadamente del Código Civil, a diferencia de lo que ocurre en el derecho español que se encuentran en el propio Código Civil.

De igual manera, se deben también contextualizar las mucho más extensas modificaciones del estatuto jurídico de los animales en el Código Civil portugués, que en buena medida obedecen a la ausencia de una legislación administrativa de protección animal tanto a nivel nacional como a nivel regional, por lo que la aprobada Ley 8/2017 de 3 de marzo, no solo pretende modificar el Código Civil, el Código del Proceso Civil y el Código

\footnotetext{
${ }^{4}$ Boletín Oficial de las Cortes Generales. Congreso de los Diputados. Serie D Núm. 108, de 22 de febrero de 2017, Págs. 6 y 7

“162/000200 El Pleno del Congreso de los Diputados, en su sesión del día de hoy, ha acordado aprobar con modificaciones la Proposición no de Ley del Grupo Parlamentario Ciudadanos, sobre la modificación del régimen jurídico de los animales de compañía en el Código Civil, publicada en el «BOCG. Congreso de los Diputados», serie D, núm. 36, de 21 de octubre de 2016, en los siguientes términos:

«El Congreso de los Diputados insta al Gobierno a:

1. Promover las reformas legales necesarias para crear una categoría especial en el Código Civil distinta a las ya previstas, referida a los animales, donde se les defina como seres vivos dotados de sensibilidad.

2. Prever las reformas legales necesarias para que los animales de compañía no puedan ser objeto de embargo en ningún procedimiento judicial.»”

http://www.congreso.es/public oficiales/L12/CONG/BOCG/D/BOCG-12-D108.PDF\#page $=6$
} 
Penal, sino más genéricamente, como indica su título, establecer un estatuto jurídico para los animales.

Ni una ni otra circunstancia están presentes en nuestro ordenamiento jurídico en el que, aunque hay disposiciones específicas de carácter administrativo sobre el comercio y utilización de animales de producción, el Código Civil y no un Código Rural, contienen las más básicas disposiciones civiles sobre unas relaciones agropecuarias socialmente mayoritarias en la fecha de aprobación del Código Civil. E inversamente a lo que sucede en Portugal, aunque estemos huérfanos de una Ley nacional de protección de los animales, lo cierto es que desde los años 90 del siglo XX es profusa y heterogénea la legislación administrativa autonómica de protección de los animales, que se aplica en todo caso a los de compañía y en muchos casos, y con distinta extensión, también al resto de animales domésticos.

Por todo ello la modificación del estatuto jurídico de los animales en el Código Civil español debe cumplir solo las únicas funciones de actualizar dicho estatuto a la consideración que tienen los animales hoy en día en la sociedad española como seres sintientes y no como cosas, y de superar los anacronismos, incongruencias con otros sectores del ordenamiento y lagunas regulativas, sobre todo en el derecho de familia, de que todavía adolece el decimonónico estatuto jurídico civil de los animales aún vigente, teniendo en cuenta para ello el ius commune que se deriva del resto de sectores del ordenamiento que han ido implementando el art. 13 del Tratado de Funcionamiento de la Unión Europea, los avances científicos en el conocimiento del bienestar animal y la experiencia que la práctica judicial ha ido revelando en los últimos tiempos a la hora de resolver los múltiples conflictos que surgen en las relaciones civiles de la convivencia entre animales y personas.

\section{ALGUNAS CONSIDERACIONES A PROPÓSITO DE LA REFORMA DEL ESTATUTO JURÍDICO CIVIL DEL ANIMAL}

Como ya se dijo, el 14 de febrero de 2017 el pleno de Congreso de los Diputados, aprobó por unanimidad instar al Gobierno a modificar el Código Civil español para que los animales dejen de ser considerados meras cosas en propiedad ${ }^{5}$. En concreto, el texto de la Enmienda transaccional a la Proposición no de Ley del Grupo parlamentario Ciudadanos, instaba al Gobierno a:

"promover las reformas legales necesarias para crear una categoría especial en el Código Civil distinta a las ya previstas, referida a los animales, donde se les defina como seres vivos dotados de sensibilidad", así como, "prever las reformas legales necesarias para que los animales de compañía no puedan ser objeto de embargo en ningún procedimiento judicial “.

Una unanimidad que se repite en la admisión a trámite por el Congreso de la Proposición de ley de modificación del Código Civil, la Ley Hipotecaria y la Ley de Enjuiciamiento Civil, sobre el régimen jurídico de los animales ${ }^{6}$. Dicha Proposición de Ley pone de relieve en su Exposición de motivos que el tenor literal del Código Civil de 1889

\footnotetext{
${ }^{5}$ Diario de Sesiones del Congreso de los Diputados, pleno y diputación permanente, Año 2017, No 29, XII Legislatura, sesión plenaria No 27, martes, 14 de febrero de 2017, págs. 43-50. http://www.congreso.es/public oficiales/L12/CONG/DS/PL/DSCD-12-PL-29.PDF; Sobre ello, cfr. CODINA, J.I., Unanimidad en el Congreso de los Diputados para instar la reforma del Código civil español y reconocer a los animales como seres dotados de sensibilidad, en dA. Derecho Animal, 2/2017 (https://derechoanimal.info/es/actividades/2017/unanimidad-en-el-congreso-de-los-diputadospara-instar-la-reforma-del-codigo-civil)

${ }^{6}$ Presentada por el Grupo Parlamentario Popular y admitida a trámite por unanimidad del Congreso de los Diputados el 13 de octubre de 2017: 
ignora que los animales son seres vivos dotados de sensibilidad y no es capaz de dar una respuesta adecuada a los múltiples conflictos actuales que se derivan de la convivencia entre personas y animales. Por ello, la Proposición de Ley trata de modernizar y actualizar la legislación civil para adecuarla al tiempo en el que tiene que ser aplicada, ofreciendo a los aplicadores del Derecho un criterio congruente para resolver los conflictos que se dan en el día a día judicial, y que por el momento obligan a los tribunales a tener que aplicar una legislación que por no contemplar los intereses más básicos de los animales, resulta anticuada y muy alejada del actual sentir social ${ }^{7}$.

Conviene resaltar que en otras regiones españolas y en otros países de la Unión Europea (UE), en los que ya se ha superado este anacronismo del estatuto jurídico civil del animal-cosa-recurso, se ha hecho teniendo en consideración a todos los animales y no sólo a los animales de compañía. Lo contrario sería un absurdo científico, ético y jurídico ya que todos los animales son seres vivos, sintientes, es decir con capacidad de sentir y ese y no otro es, como ha quedado expuesto reiteradamente a lo largo de este informe, el mandato del artículo 13 del TFUE, referido a todos los animales.

En el ámbito europeo, como hemos visto, además de Francia en 2015 y Portugal en 2017, que han sido los países que más recientemente han actualizado sus legislaciones civiles, otros destacados Estados miembros de la UE ya habían modificado en idéntico sentido sus Códigos Civiles, adecuando decimonónicos textos legales a los tiempos actuales y reconociendo a todos animales, sin exclusiones, como seres sintientes.

El primero en hacerlo fue Austria ${ }^{8}$ en 1988, estableciendo que los animales no son cosas, que están protegidos por las leyes y que las disposiciones referidas a las cosas se les aplican sólo en caso de no existir otra previsión diferente. El segundo fue Alemania ${ }^{9}$ en 1990 , aclarando que los animales no son cosas, que están protegidos por leyes especiales y que sólo se les aplicarán las disposiciones sobre las cosas con carácter supletorio en defecto de otras. El tercer país en reformar su Código Civil fue Suiza ${ }^{10}$ en 2002, entrando en vigor la reforma en 2003 y reconociendo nuevamente que los animales no son cosas y que están protegidos por su legislación especial y también, aunque fuera de la Unión Europea, hizo la misma reforma Liechtenstein ${ }^{11}$ en 2003.

Dentro del Derecho Civil foral, Cataluña ${ }^{12}$ modificó en 2006 el estatuto jurídico civil de los animales, especificando que no son cosas y que solo se les aplican las reglas de los bienes en lo que permita su naturaleza, y haciendo una remisión normativa a la legislación especial.

\footnotetext{
${ }^{7}$ Diversos colegios de Abogados de España (Oviedo, Madrid, Málaga, Álava, Vigo, Lanzarote, Estella, Girona, Reus, Córdoba y Talavera) han suscrito el manifiesto "La superación del Estatuto Jurídico Civil del animal-cosa como forma de resolución de conflictos" en el que se apoya la iniciativa dirigida a este cambio legal (http://www.abogacia.es/2018/01/10/el-ica-oviedo-lanza-un-manifiesto-para-que-elcodigo-civil-deje-de-considerar-a-los-animales-como-cosas/)

${ }^{8} \S 285$ a Allgemeines Bürgeliches Gesetzbuch, introducido por la Bundesgesetz über die Rechtsstellung von Tieren, de 10 de marzo de 1988.

9 Véase el § 90a Bürgerliches Gesetzbuch, introducido por la Gesetz zur Verbesserung der Rechtsstellung des Tieres im bürgerlichen Recht, de 25 de agosto de 1990.

${ }^{10}$ Véase el art. 641a Zivilgesetzbuch, introducido por la Zivilgesetzbuch, Obligationenrecht, Strafgesetzbuch, Bundesgesetz über Schuldbetreibung und Konkurs (Grundsatzartikel Tiere) de 4 de octubre de 2002, en vigor desde el 1 de abril de 2003.

${ }^{11}$ Veáse el art. 20a Sachenrecht Gesetzbuch, introducido por la Ley de modificación publicada en el Landesgesetzblatt $\mathrm{N}^{\circ} 155$ de 2003.

${ }^{12}$ El artículo 511-1.3 dispone expresamente que: “Los animales, que no se consideran cosas, están bajo la protección especial de las leyes. Solo se les aplican las reglas de los bienes en lo que permite su naturaleza”. Fue introducido por la Ley 5/2006, de 10 de mayo, del libro quinto del Código Civil de Cataluña, relativo a los derechos reales.
} 
Fuera del ámbito europeo, otros países como Canadá ${ }^{3}$, Nueva Zelanda ${ }^{14}$ o Colombia ${ }^{15}$ también han reconocido en sus legislaciones a los animales (todos ellos) como seres sintientes. También es reseñable que Brasil ${ }^{16}$ y Argentina ${ }^{17}$ se encuentran en estos momentos sendos Proyectos de Ley de modificación del Código Civil, siguiendo la tramitación parlamentaria correspondiente para llevar a cabo idéntica reforma de modernización del estatuto jurídico civil de los animales.

Si sale adelante la mencionada Proposición de Ley de modificación del Código Civil, la Ley Hipotecaria y la Ley de Enjuiciamiento Civil, sobre el régimen jurídico de los animales, la superación de este anacrónico estatuto jurídico del animal como cosa no solo adecuará nuestro Código Civil al sentir social, ético y jurídico actual, sino que contribuirá a solucionar no pocos problemas que surgen en la resolución cotidiana de conflictos privados. Conviene recordar en este sentido que la legislación civil tiene su ámbito de aplicación circunscrito a la regulación del derecho privado y esta reforma, aunque se refiera al estatuto jurídico de los animales, se reduce al Derecho Civil y a las relaciones privadas, sin que resulte de aplicación a otros ámbitos con incidencia en los animales como pueden ser los espectáculos públicos, que tienen su propia legislación especial, nacional y autonómica ${ }^{18}$.

\footnotetext{
${ }^{13}$ Véase el art. 898.1 Code Civil du Quebec, introducido por la Loi sur la protection sanitaire des animaux, de 4 de diciembre de 2015.

${ }^{14}$ Véase el Title Paragraph (a)(i) Animal Welfare Act of 1999, en la redacción dada por la Animal Welfare Amendment Act, de 10 de mayo de 2015.

${ }^{15}$ El art. 655.2 Código Civil de Colombia reconoce a todos los animales como seres sintientes. Fue introducido por Ley 1774 de 6 de enero de 2016, por medio de la cual se modifican el Código Civil, la Ley 84 de 1989, el Código Penal, el Código de Procedimiento Penal y se dictan otras disposiciones. http://es.presidencia.gov.co/normativa/normativa/LEY\%201774\%20DEL\%206\%20DE\%20ENERO\% 20DE\%202016.pdf
}

${ }^{16}$ Projeto de Lei do Senado Brasil, n³52, de 2015. Altera a Lei no 10.406 , de 10 de janeiro de 2002 (Código Civil), para determinar que os animais não sejam considerados coisas, mas bens móveis para os efeitos legais, salvo o disposto em lei especial.

https://www25.senado.leg.br/web/atividade/materias/-/materia/121697 PL 3670/2015, Câmara dos Deputados Brasil http://www.camara.gov.br/proposicoesWeb/fichadetramitacao?idProposicao=2055720

${ }^{17}$ Proyecto de Ley del Senado de la Nación Argentina, modificando la Ley 26.994 - Código Civil y Comercial de la Nación-, respecto de incorporar a la misma el régimen de los animales. http://www.senado.gov.ar/parlamentario/comisiones/verExp/1555.16/S/PL

${ }^{18}$ La tauromaquia se rige por su normativa específica al igual que el resto de Espectáculos Públicos cuya legislación especial está conformada, tanto en el ámbito nacional, por el Real Decreto 2816/1982, de 27 de agosto, por el que se aprueba el Reglamento General de Policía de Espectáculos Públicos y Actividades Recreativas como en el ámbito autonómico por las siguientes leyes:

- Ley 13/1999, de 15 de diciembre, de Espectáculos Públicos y Actividades Recreativas de Andalucía (BOE núm. 15, de 18 de enero), modificada por la Ley 10/2002, de 21 de diciembre (BOE núm. 14, de 16 de enero de 2003).

- Ley 11/2005, de 28 de diciembre, reguladora de los espectáculos públicos, actividades recreativas y establecimientos públicos de la Comunidad Autónoma de Aragón (BOE núm. 23, de 27 de enero), modificada por la Ley 7/2011, de 10 de marzo (BOE núm. 98, de 25 de abril) y por la Ley 5/2016, de 2 de junio (BOE núm. 156, de 29 de junio).

- Ley 7/2011, de 5 de abril, de actividades clasificadas y espectáculos públicos y otras medidas administrativas complementarias (BOE núm. 109, de 7 de mayo.

- Ley 2/2015, de 1 de octubre, por la que se aprueba el régimen sancionador en materia de espectáculos públicos, actividades recreativas y establecimientos públicos en la Comunidad Autónoma de Cantabria (BOE núm. 247, de 15 de octubre).

- Ley 7/2011, de 21 de Marzo, de Espectáculos Públicos, Actividades Recreativas y Establecimientos Públicos de Castilla-La Mancha (BOE núm. 105, de 3 de mayo).

- Ley 7/2006, de 2 de octubre, de espectáculos públicos y actividades recreativas de la Comunidad de Castilla y León (BOE núm. 272, de 14 de noviembre).

- Ley 11/2009, de 6 de julio, de regulación administrativa de los espectáculos públicos y las actividades recreativas (BOE núm. 186, de 3 de agosto). 


\section{PROPUESTA DE REFORMA CONTENIDAS EN LA PROPOSICIÓN DE LEY}

Como se puede comprobar leyendo el texto de la Proposición de Ley en tramitación, la misma opta, en línea con lo que se propugnaba en el Informe sobre la reforma del Estatuto Jurídico Civil de los animales en España antes mencionado, por un modelo de reforma que toma lo mejor del modelo catalán, del modelo francés y del más reciente modelo portugués y que, además aporta soluciones específicas a las necesidades propias de la legislación civil común española. Aunque la Proposición de Ley inicial ha sido objeto de proposición de enmiendas ninguna de ellas lo es a la totalidad, ni implica una modificación o rechazo sustancial a ninguno de los cambios propuestos inicialmente, y consisten sustancialmente en enmiendas de carácter técnico y de detalle ${ }^{19}$.

En congruencia con lo anterior, la propuesta de reforma del Código Civil para actualizar el estatuto jurídico civil de los animales, adecuándolo al sentir social actual y al respeto a su bienestar y protección que informan al resto del Ordenamiento Jurídico:

1. Reconoce expresamente en el art. 333.1 CC la sintiencia animal a todos los animales.

2. Introduce en el ámbito civil los mandatos de tenencia responsable y atención y cuidados debidos. En este sentido, aunque los animales dejan de ser considerados bienes muebles o inmuebles, pueden ser objeto de apropiación con las limitaciones que se establezcan en las normas legales y en la medida en que no lo prohíban (nuevo art. 333 bis CC). Su propietario, no obstante, debe respetar

- Ley 17/1997, de 4 de julio, de Espectáculos Públicos y Actividades Recreativas (BOE núm. 98, de 24 de abril de 1998), modificada por la Ley 24/1999, de 27 de diciembre (BOE núm. 48, de 25 de febrero de 2000), por la Ley 5/2000, de 8 de mayo (BOE núm. 126, de 26 de mayo), por la Ley 5/2002, de 27 de junio (BOE núm. 176, de 24 de julio), por la Ley 4/2013, de 18 de diciembre (BOE núm. 74, de 26 de marzo) y por la Ley 5/2015, de 18 de diciembre (BOE núm. 66, de 17 de marzo).

- Ley Foral 2/1989, de 13 de marzo, Reguladora de los Espectáculos Públicos y Actividades Recreativas (BOE núm. 84, de 8 de abril), modificada por la Ley Foral 26/2001, de 10 de diciembre (BOE núm. 39, de 14 de febrero de 2002).

- Ley 14/2010, de 3 de diciembre, de espectáculos públicos, actividades recreativas y establecimientos públicos (BOE núm. 316, de 29 de diciembre).

- Ley 4/2016, de 6 de mayo, para el establecimiento de un régimen sancionador en materia de espectáculos públicos y actividades recreativas en la Comunidad Autónoma de Extremadura (BOE núm. 132, de 1 de junio).

- Ley 7/1999, de 8 de abril, de Atribución de Competencias a los Consejos Insulares de Menorca y de Eivissa i Formentera en materia de Espectáculos Públicos y Actividades Recreativas (BOE núm. 124 , de 25 de mayo).

- Ley 4/2000, de 25 de octubre, de Espectáculos Públicos y Actividades Recreativas. (BOE núm. 287, de 30 de noviembre).

- Ley 10/2015, de 23 de diciembre, de la Comunidad Autónoma del País Vasco, de Espectáculos Públicos y Actividades Recreativas (BOE núm. 23, de 27 de enero).

- Ley 8/2002, de 21 de octubre, de Espectáculos Públicos y Actividades Recreativas. (BOE núm. 278, de 20 de noviembre).

- Ley 2/2011, de 2 de marzo, de admisión en espectáculos públicos, actividades recreativas y establecimientos públicos de la Región de Murcia. (BOE núm. 39, de 15 de febrero de 2012)

- Ley 9/2016, de 2 de junio, de medidas urgentes en materia de espectáculos públicos en la Comunidad Autónoma de la Región de Murcia. (BOE núm. 153, de 25 de junio)

- ${ }^{19}$ Véanse las enmiendas y el índice de enmiendas al articulado de Proposición de Ley de modificación del Código Civil, la Ley Hipotecaria y la Ley de Enjuiciamiento Civil, sobre el régimen jurídico de los animales, publicadas en el Boletín Oficial de las Cortes Generales. Congreso de los Diputados. Serie B Núm. 167-4, de 27 de marzo de 2018, http://www.congreso.es/public_oficiales/L12/CONG/BOCG/B/BOCG-12-B-167-4.PDF\#page=1 
su cualidad de ser dotado de sensibilidad, asegurando su bienestar conforme a las características de cada especie, no pudiendo maltratarlo, ni abandonarlo o sacrificarlo salvo en los casos establecidos en las normas legales o reglamentarias (art. 333.3 CC).

3. Contiene remisiones normativas expresas a la legislación especial de protección de los animales ya existente (dotando de seguridad jurídica y coherencia interna al Ordenamiento Jurídico) en cuestiones como la ocupación (art. 610 CC). Y aunque no se han derogado preceptos del CC, como el art. 611 sobre el hallazgo de animales, sí se ha redactado teniendo en cuenta la legislación administrativa de protección de animales abandonados para evitar contradicciones con ella.

4. Reformula las disposiciones relativas tanto a la responsabilidad civil por daños causados por terceros a los animales (art. 333.3 CC) como al saneamiento por vicios ocultos en la compraventa de animales (art. 1484 CC) para abarcar los gastos derivados de la asistencia veterinaria y los cuidados necesarios para garantizar la salud y el bienestar de los animales, de conformidad con las leyes especiales, como seres sintientes que son. Del mismo modo, el propietario y quienes convivan con el animal tendrán derecho en los casos de responsabilidad civil a una indemnización, que será fijada equitativamente por el tribunal, por el sufrimiento moral sufrido (art. 333.4 CC).

5. Obliga a estipular en el Convenio regulador de las relaciones matrimoniales, si lo hubiere, el destino de los animales de compañía, caso de que existan, teniendo en cuenta el interés de los miembros de la familia y el bienestar del animal, pudiendo preverse el reparto de los tiempos de disfrute si fuere necesario (art. 90.1.c) CC). Igualmente en caso de separación (nuevo art. 94 bis CC) o divorcio (art. 103.2 CC) la reforma prevé que la autoridad judicial disponga sobre la custodia de los animales de compañía y los derechos de visita del cónyuge a quien no se confíen, atendiendo al interés de los miembros de la familia y al bienestar del animal.

6. Declara expresamente, mediante una modificación del art. 605 de la Ley de Enjuiciamiento Civil, la inembargabilidad de los animales de compañía, de conformidad con lo requerido el texto de la Enmienda Transaccional a la Proposición No de Ley aprobada por unanimidad del Pleno de Congreso de los Diputados en febrero de 2017. También modifica el art. 111 de la Ley hipotecaria para que la garantía hipotecaria de los bienes inmuebles no comprenda, ni con pacto expreso, a los animales de compañía, pudiendo comprender a los demás animales solo en caso de que así se acuerde expresamente o lo disponga otra disposición legal.

Finalmente, también cabe reseñar que el Observatorio Justicia y Defensa Animal y la Fundación Affinity han vuelto a proponer a los distintos grupos parlamentarios otra serie de recomendaciones basadas en las conclusiones del Informe anteriormente referido, que pueden ser tenidas en cuenta en el trámite de enmiendas en el Congreso, entre las que cabe citar: el añadido de un nuevo apartado al artículo 1346 que permita la consideración de privativos de cada cónyuge los animales de compañía que estaban bajo el cuidado cada miembro de la pareja antes de contraer matrimonio; incluir remisiones normativas a la legislación especial de protección animal en la Exposición de Motivos, en el artículo 465, 610 y 1800 del Código Civil y la creación de un nuevo artículo 1091 bis que determine, respecto a las cesiones de animales entre particulares, que se estará a lo dispuesto en el contrato y, en todo caso, al cumplimiento de la legislación especial de protección animal que resulte de aplicación. 